\title{
Degradation of chloramphenicol by UV/chlorine treatment: Kinetics, mechanism and enhanced formation of halonitromethanes
}

\author{
Huiyu Dong, Zhimin Qiang*, Jun Hu, Jiuhui Qu \\ Key Laboratory of Drinking Water Science and Technology, Research Center for Eco-Environmental Sciences, University of Chinese Academy of Sciences,
} Chinese Academy of Sciences, 18 Shuang-qing Road, Beijing 100085, China

\section{A R T I C L E I N F O}

\section{Article history:}

Received 6 February 2017

Received in revised form

12 May 2017

Accepted 13 May 2017

Available online 17 May 2017

\section{Keywords:}

UV/chlorine

Chloramphenicol

Halonitromethanes

Kinetics

\begin{abstract}
A B S T R A C T
Ultraviolet (UV)/chlorine process is considered as an emerging advanced oxidation process for the degradation of micropollutants. This study investigated the degradation of chloramphenicol (CAP) and formation of disinfection by-products (DBPs) during the UV/chlorine treatment. It was found that CAP degradation was enhanced by combined UV/chlorine treatment compared to that of UV and chlorination treatment alone. The pseudo-first-order rate constant of the UV/chlorine process at $\mathrm{pH} 7.0$ reached $0.016 \mathrm{~s}^{-1}$, which was 10.0 and 2.0 folds that observed from UV and chlorination alone, respectively. The enhancement can be attributed to the formation of diverse radicals ( $\mathrm{HO} \cdot$ and reactive chlorine species (RCSs)), and the contribution of RCSs maintained more stable than that of $\mathrm{HO} \cdot$ at $\mathrm{pH}$ 5.5-8.5. Meanwhile, enhanced DBPs formation during the UV/chlorine treatment was observed. Both the simultaneous formation and 24-h halonitromethanes formation potential (HNMsFP) were positively correlated with the $\mathrm{UV} /$ chlorine treatment time. Although the simultaneous trichloronitromethane (TCNM) formation decreased with the prolonged UV irradiation, TCNM dominated the formation of HNMs after $24 \mathrm{~h}$ $(>97.0 \%)$. According to structural analysis of transformation by-products, both the accelerated CAP degradation and enhanced HNMs formation steps were proposed. Overall, the formation of diverse radicals during the UV/chlorine treatment accelerated the degradation of CAP, while also enhanced the formation of DBPs simultaneously, indicating the need for DBPs evaluation before the application of combined UV/chlorine process.
\end{abstract}

() 2017 Elsevier Ltd. All rights reserved.

\section{Introduction}

Due to extensive human and veterinary utilization and the selective proliferation of antibiotic resistant bacteria, antibiotic pollution has attracted increasing concerns recently (Dong et al., 2016). As a broad-spectrum antibiotic with excellent antibacterial activity, chloramphenicol (CAP) has been widely used in clinical prescriptions, animal husbandry and aquaculture (Sapkota et al., 2008). More than $30 \%$ of CAP intake can leave the organisms without degradation via feces or urine. Meanwhile, the removal of CAP by wastewater treatment plants (WWTPs) is also limited, which inevitably leads to wide detection of CAP in the effluent of WWTPs, surface water and even drinking water (Shao et al., 2009). In the Pearl River of China, the CAP concentration was observed in the range of $11-266 \mathrm{ng} \mathrm{L}^{-1}$ (Xu et al., 2007). Moreover, because of

\footnotetext{
* Corresponding author.

E-mail address: qiangz@rcees.ac.cn (Z. Qiang).
}

its low molecular weight (chemical structure in Fig. S1) and high hydrophilicity ( $2500 \mathrm{mg} \mathrm{L}^{-1}$ solubility at $25^{\circ} \mathrm{C}$ ), CAP cannot be effectively removed by conventional drinking water treatment processes (i.e., coagulation, sedimentation and filtration), indicating the potential occurrence of CAP in drinking water (Mompelat et al., 2009). For example, $28.4 \mathrm{ng} \mathrm{L}^{-1}$ CAP was detected in the drinking water supply in Shanghai, China (Jiang et al., 2011).

Continuous efforts have been made to develop advanced oxidation processes (AOPs) for the abatement of micropollutants from water. As a green disinfection technology in water treatment, ultraviolet (UV) is usually combined with chlorine to achieve multiple-barrier disinfection and maintain residual protection. With chlorine addition before or during UV disinfection, the combined use of UV and free chlorine (FC) has become an emerging AOP (i.e. UV/chlorine), not only for inactivation of water-borne pathogens, but also for the degradation of micropollutants (Xiang et al., 2016). Previous studies have reported the enhanced degradation of organic pollutants by the UV/chlorine process, which involves a series of chain reactions that initiated by reactive chlorine species 
(RCSs including $\mathrm{Cl} \bullet$ and $\mathrm{Cl} \cdot \frac{-}{2}$ ) and $\mathrm{HO} \cdot$ radical (Eqs. (1)-(5)) (Watts and Linden, 2007; Chan et al., 2012). HO• is a nonselective oxidant, while $\mathrm{Cl} \cdot$ and $\mathrm{Cl}_{-}^{-}$are selective oxidants that preferably react with electron-rich moieties through one-electron oxidation, $\mathrm{H}$-abstraction, and addition to unsaturated $\mathrm{C}-\mathrm{C}$ bonds (Grebel et al., 2010; Lee and von Gunten, 2010). The oxidation potentials of $\mathrm{Cl} \cdot$ and $\mathrm{Cl}^{\circ} \overline{2}$ are $2.47 \mathrm{~V}$ and $2.0 \mathrm{~V}$, respectively (Beitz et al., 1998; Hirakawa and Nosaka, 2002), indicating higher kinetics constants with micropollutants than $\mathrm{HO}$ (Fang et al., 2014). UV/chlorine was reported to be more efficiently than the $\mathrm{UV} / \mathrm{H}_{2} \mathrm{O}_{2}$ process in degrading micropollutants (Sichel et al., 2011).

$$
\begin{aligned}
& \mathrm{HOCl} \rightarrow \mathrm{H}^{+}+\mathrm{OCl}^{-} \\
& \mathrm{HOCl}+h v \rightarrow \mathrm{HO}^{\cdot}+\mathrm{Cl}^{\cdot} \\
& \mathrm{OCl}^{-}+h v \rightarrow \mathrm{O}^{-}+\mathrm{Cl}^{\cdot} \\
& \mathrm{O}^{--}+\mathrm{H}_{2} \mathrm{O} \rightarrow \mathrm{HO}^{\cdot}+\mathrm{OH}^{-} \\
& \mathrm{Cl}^{-}+\mathrm{OH}^{-} \rightarrow \mathrm{ClHO}^{-}
\end{aligned}
$$

Although the formation of diverse reactive species in the UV/ chlorine system is beneficial in terms of micropollutants degradation, it may induce disinfection by-products (DBPs) formation and the DBPs (and their formation mechanisms) can be different from those formed during UV irradiation or chlorination alone. Enhanced chloroform (Liu et al., 2006), N-nitrosodimethylamine and cyanogen chloride (Weng et al., 2012; Soltermann et al., 2013) formations by the $\mathrm{UV} /$ chlorine treatment have been observed compared to chlorination alone.

The formation of nitrogenous DBPs (N-DBPs) is a growing concern for water utilities using impaired source waters with wastewater effluent discharges or algal blooms, because of elevated concentrations of dissolved organic nitrogen as N-DBPs precursors (Chu et al., 2011, 2014). Among 50 high priority DBPs monitored in a 2000-2002 U.S. nationwide survey at drinking water treatment plants, the cytotoxicity (measured with in vitro mammalian cell tests) of halonitromethanes (HNMs) could be several orders of magnitude higher than currently regulated trihalomethanes and haloacetic acid (Krasner et al., 2006). The chemical structure of HNMs contains a nitro group and different halogens on the $\alpha$-carbon, which could be formed from chlorination or chloramination of nitrogen-containing precursors (e.g., primary amines, amino acids, nucleic acids and pharmceuticals) (Chu et al., 2016). Nine HNMs have been identified including mono-, di- and tri-halogenated species (i.e., trichloronitromethane (TCNM), bromodichloronitromethane (BDCNM), dibromochloronitromethane (DBCNM), tribromonitromethane (TBNM), dichloronitromethane (DCNM), bromochloronitromethane (BCNM), dibromonitromethane, chloronitromethane (MCNM), and bromonitromethane). The chemical structure of CAP contains amine and nitro groups, both of which are potent HNMs precursors. HNMs formation from CAP during chlorination and $\mathrm{UV} /$ chlorine treatment is gaining concerns because of their potent cytotoxicity, genotoxicity, and carcinogenicity. However, to our best knowledge, the evaluation of HNMs formation during the UV/chlorine treatment of pharmaceuticals was rarely reported.

To fill this knowledge gap, this work comparatively studies the degradation kinetics of CAP in the UV, chlorination and UV/chlorine processes, and evaluates the contributions of reactive radical species during the UV/chlorine treatment. We further investigate the HNMs formations during and after the UV/chlorine treatment of CAP. Results from this work help reveal the mechanisms for CAP degradation and DBPs formation during UV/chlorine treatment, which has important implications in ensuring drinking water safety.

\section{Materials and methods}

\subsection{Materials}

All chemicals were at least of analytical grade and used without further purification. Individual HNMs including MCNM, DCNM, TCNM, BDCNM, DBCNM, and TBNM were all purchased from CanSyn Chem. Co. (New Westminister, BC, Canada). A standard mixture of four regulated trihalomethanes (THMs) including bromodichloromethane, tribromethane, trichloromethane and dibromochloromethane and an internal standard of 1,2-dibromopropane were purchased from J\&K Chemical Co. (Beijing, China). Ammonium sulfate (99\%), sodium sulfite (99\%), potassium bromide (99\%), sulfuric acid (99\%), sodium hydroxide (99\%), $\mathrm{NaOCl}$ (5\% of active chlorine) and nitrobenzene (NB) were obtained from Sinopharm Chemical Reagent Co. (Shanghai, China). High performance liquid chromatography (HPLC) grade methanol $(\mathrm{MeOH})$, and acetonitrile (ACN) were purchased from Fisher Scientific (Belgium). Formic acid (HPLC grade) was from Dikma Technologies (USA). All solutions were prepared in deionized water $(18.2 \mathrm{M} \Omega \mathrm{cm})$ produced by a Milli-Q system (Advantage A10, Millipore, Billerica, MA, USA).

\subsection{Experimental procedures}

\subsubsection{Chlorination}

Chlorination experiments were carried out in a $1000 \mathrm{~mL}$ batch reactor equipped with a stirred bar to ensure homogeneous reaction. Experiments were initiated by adding calculated aliquots of concentrated FC solution ( $10 \mathrm{mM}$ ) to the reactor containing desired CAP and chlorine. $2 \mathrm{mM}$ phosphate buffer was used for $\mathrm{pH}$ 5.5-8.5, which was adjusted with small volumes of $0.1 \mathrm{M} \mathrm{H}_{2} \mathrm{SO}_{4}$ and $\mathrm{NaOH}$.

\subsubsection{UV irradiation}

The UV irradiation reactor containing a glass reactor (i.d. $=10.0 \mathrm{~cm}$, height $=25.0 \mathrm{~cm}$ ) and a constant temperature water bath coupled with diaphragm pump are shown in Fig. S2. The temperature of the UV system was controlled at $25^{\circ} \mathrm{C}$ by circulating the water in the bath. A $400 \mathrm{~mL}$ quartz tube (i.d. $=4.5 \mathrm{~cm}$ ) and a low pressure (LP) Hg UV lamps (Heraeus, GPH 212T5L/4, 10 W, $254 \mathrm{~nm}$ ) were fixed in the center of the $1000 \mathrm{~mL}$ UV reactor, which was magnetically mixed at the bottom of the reactor. The photo flux $\left(\mathrm{I}_{0}\right)$ was determined to be $0.75 \mathrm{mE} \mathrm{s}^{-1}$ for kinetic tests via iodide-iodate chemical actinometry (Bolton and Linden, 2003). The effective path length (L) was determined to be $7.2 \mathrm{~cm}$ by measuring the photolysis rate of $\mathrm{H}_{2} \mathrm{O}_{2}$ and the average UV fluence rate (irradiance) was determined to be $2.1 \mathrm{~mW} \mathrm{~cm}^{-2}$ (Garoma and Gurol, 2005).

\subsubsection{DBPs formation}

DBPs formation analysis was conducted during and after (24 h) the UV/chlorine treatment of CAP. For the simultaneous formation of HNMs during the UV/chlorine treatment, $50 \mu \mathrm{M}$ CAP and $0.5 \mathrm{mM}$ chlorine were dosed with various UV/chlorine treatment times (0-30 min). Then an aliquot of sample was quenched for the analysis of simultaneous HNMs formation by ascorbic acid at a molar concentration that was twice the initial molar concentration of the chlorine at the scheduled time. For the DBPs formation potential (DBPsFP) test, an aliquot of sample $(45 \mathrm{~mL})$ with different UV/chlorine treatment times (0-30 min) was taken and additional chlorine was added to reach the $0.5 \mathrm{mM}$ dose for incubation for DBPsFP analysis (including THMs and HNMs). DBPsFP test was performed in triplicate in the dark using $50 \mathrm{~mL}$ headspace-free 
screw-cap amber glass vials with PTFE-lined septa at $25^{\circ} \mathrm{C}$. After $24 \mathrm{~h}$, the samples were quenched and analyzed immediately to investigate the effect of $\mathrm{UV} /$ chlorine treatment on DBPs formation. The HNMs formation potential (HNMsFP) of a water sample is the sum of MCNM, DCNM and TCNM formation during the DBPsFP test.

\subsection{Analysis}

The quantifications of the CAP were performed with an Agilent 1200 Series HPLC (CA, USA) equipped with Atlantis C18 column $(4.6 \times 250 \mathrm{~mm}, 5.0 \mu \mathrm{m}$; Waters, MA, USA) at an UV wavelength of $278 \mathrm{~nm}$. The mobile phase was a mixture of $\mathrm{MeOH} /$ water in 70/30 $(\mathrm{v} / \mathrm{v})$ ratio. The flow rate was set at $0.7 \mathrm{~mL} \mathrm{~min}^{-1}$ and the injection volume was $50 \mu \mathrm{L}$. The temperature of the column was set at $25^{\circ} \mathrm{C}$. The formation of DBPs was analyzed after samples were extracted with methyl tert-butyl ether using a gas chromatograph (7890, Agilent, CA, USA) equipped with a HP 5 fused silica capillary column ( $30 \mathrm{~m} \times 0.25 \mathrm{~mm}$ i.d., $0.25 \mu \mathrm{m}$ film thickness, J\&W, CA, USA) and an electronic capture detector using the modified USEPA method 551.1 (Munch and Hautman, 1995). Chlorine concentration was measured using the $N, N$-diethyl- $p$-phenylenediamine (DPD) method (APHA, 1998).

To identify the other non-volatile transformation by-products (TBPs) during CAP degradation by the UV/chlorine treatment, the reaction was allowed to proceed for $24 \mathrm{~h}$ and then water samples were quenched before analysis. The TBPs of CAP were identified by ultra-performance liquid chromatography-tandem mass spectrometry (UPLC-MS/MS, Agilent 1290 Infinity LC, Agilent 6420 Triple Quad LC/MS detector, CA, USA) coupled with an Acquity $\mathrm{CSH}^{\text {TM }} \mathrm{C} 18$ column $(2.1 \times 100 \mathrm{~mm}, 1.7 \mu \mathrm{m})$ (Waters, MA, USA). Elution gradient with two mobile phases, including ACN with $0.1 \%$ formic acid (A) and MQ water with $0.1 \%$ formic acid (B), was programmed as follows (min, \%A): $(0,10),(1,10),(5,90),(6,90),(6.5$, $10)$, and $(12,10)$. The flow rate was $0.3 \mathrm{~mL} \mathrm{~min}^{-1}$ and the column temperature was held constant at $25^{\circ} \mathrm{C}$ with an injection volume of $20 \mu \mathrm{L}$. The structural identification of the TBPs was analyzed in both total ion chromatogram (TIC) and selected ion monitoring (SIM) modes.

\section{Results and discussion}

\subsection{CAP degradation}

As shown in Fig. 1, CAP degradation by UV/chlorine treatment was significantly faster than that by the UV and chlorination process. After $180 \mathrm{~s}$, the removal efficiency of CAP by the UV/chlorine can exceed $95 \%$, while that by UV and chlorination alone was only $25 \%$ and $75 \%$, respectively. The degradation kinetics data of all three treatments were best fitted by the pseudo-first-order kinetics model (Eq. (6)). The $k_{\text {obs,T }}$ values of the UV/chlorine processes was $0.016 \mathrm{~s}^{-1}$, which was 10 folds $\left(0.0016 \mathrm{~s}^{-1}\right)$ and 2 folds $\left(0.0081 \mathrm{~s}^{-1}\right)$ that observed from UV and chlorination alone, respectively. It is worthy to note that the $k_{\text {obs, }}$ value of the UV/chlorine $\left(0.016 \mathrm{~s}^{-1}\right)$ was actually 1.6 folds of the sum of those of the $\mathrm{UV}\left(0.0016 \mathrm{~s}^{-1}\right)$ and chlorination $\left(0.0081 \mathrm{~s}^{-1}\right)$, indicating the formation of radicals during the combined UV/chlorine treatment for the accelerated CAP degradation.

$\ln \frac{[\mathrm{CAP}]}{[\mathrm{CAP}]_{\mathrm{o}}}=-k_{\mathrm{obs}, \mathrm{T}} t$

where $k_{\mathrm{obs}, \mathrm{T}}$ is the observed pseudo-first-order degradation rate constant $\left(\mathrm{s}^{-1}\right)$.

Effect of initial chlorine concentration on the CAP degradation in the UV/chlorine process is shown in Fig. 2. With the initial chlorine

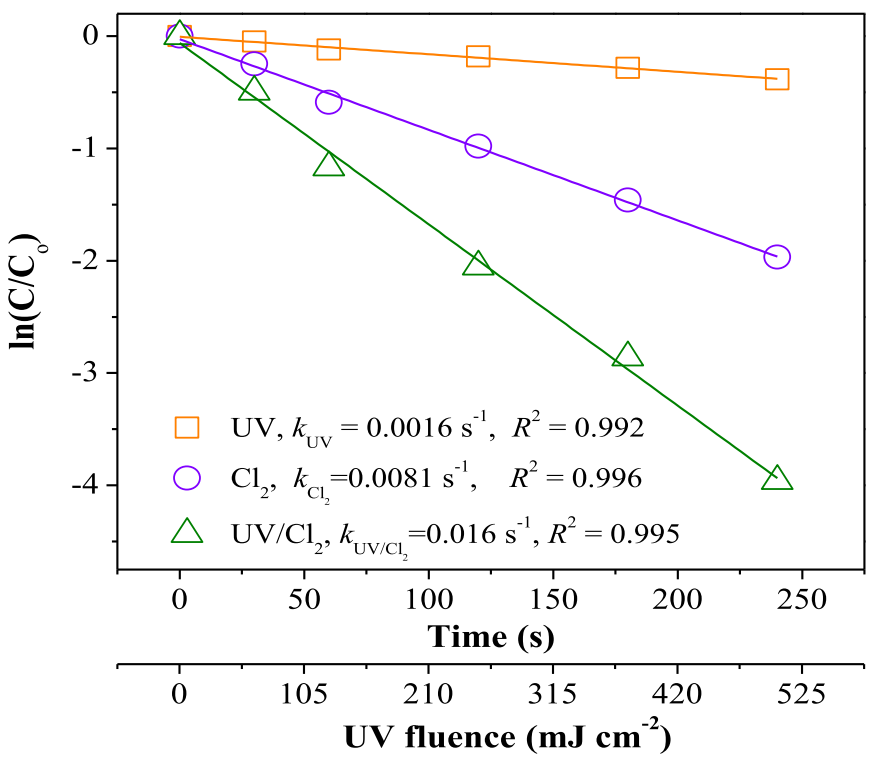

Fig. 1. Degradation of CAP by the UV, chlorine and UV/chlorine processes. Experimental conditions: $[\mathrm{CAP}]_{\mathrm{o}}=50 \mu \mathrm{M}, \quad[\text { chlorine }]_{\mathrm{o}}=0.5 \mathrm{mM}, \quad$ UV intensity $=2.1 \mathrm{~mW} \mathrm{~cm}{ }^{-2}$, $\mathrm{pH} 7.0$ adjusted by $2 \mathrm{mM}$ phosphate buffer, $\mathrm{T}=25^{\circ} \mathrm{C}$

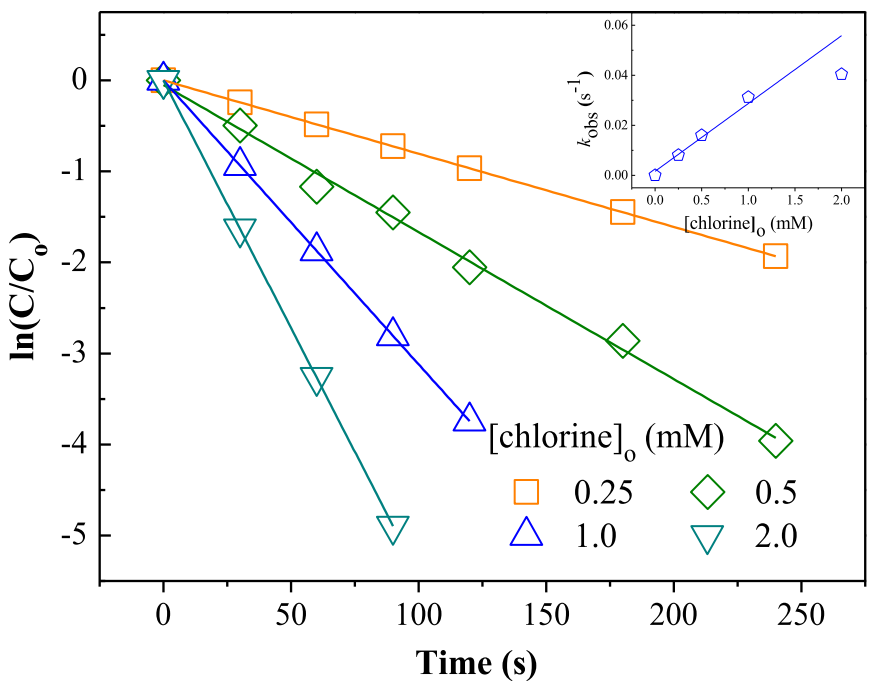

Fig. 2. Effect of initial chlorine concentration on the degradation of CAP by the UV chlorine treatment. Experimental conditions: [CAP] $]_{0}=50 \mu \mathrm{M}$, UV intensity $=2.1 \mathrm{~mW} \mathrm{~cm}^{-2}$, pH 7.0 adjusted by $2 \mathrm{mM}$ phosphate buffer, $\mathrm{T}=25^{\circ} \mathrm{C}$.

dosages in the range of $0.25-1.0 \mathrm{mM}$, the $k_{\mathrm{obs}, \mathrm{T}}$ values were linearly proportional to the chlorine concentration, indicating the kinetics of CAP degradation in the UV/chlorine process were second-order reactions, i.e., first-order relative to the CAP concentration and first-order relative to the chlorine concentration. It is well known that in the UV/chlorine process, the quantum yield of active chlorine (to produce radicals) increased with increasing active chlorine concentration (Feng et al., 2007). However, the $k_{\text {obs,T }}$ value of CAP did not increase linearly as chlorine dosage increased beyond $1.0 \mathrm{mM}$, probably due to excess chlorine acting as a radical scavenger.

\subsection{Mechanism}

\subsubsection{Chlorination}

Fig. $3 \mathrm{~A}$ shows the measured $k_{\mathrm{obs}, \mathrm{T}}$ of CAP degradation by 

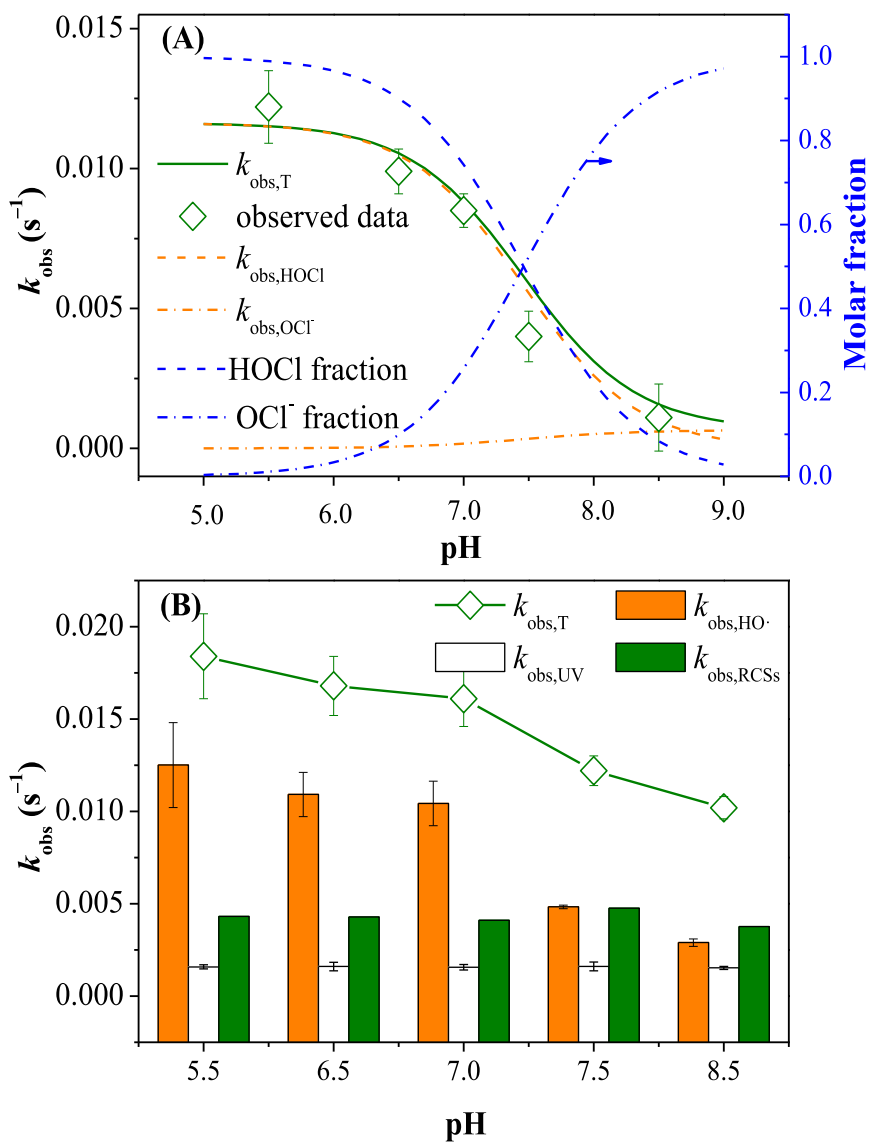

Fig. 3. Effect of $\mathrm{pH}$ on the specific first-order degradation rate constants of CAP by chlorination (A) and UV/chlorine (B) treatments. Experimental conditions: $[\mathrm{CAP}]_{\mathrm{o}}=50 \mu \mathrm{M}$, [chlorine $]_{\mathrm{o}}=0.5 \mathrm{mM}$, UV intensity $=2.1 \mathrm{~mW} \mathrm{~cm}{ }^{-2}, \mathrm{pH}$ adjusted by $2 \mathrm{mM}$ phosphate buffer, $\mathrm{T}=25^{\circ} \mathrm{C}$. Error bars represent the $95 \%$ confidence interval.

chlorination at different pHs. It was found that the CAP degradation rate decreased as $\mathrm{pH}$ increased. The $k_{\mathrm{obs}, \mathrm{T}}$ value was $0.13 \mathrm{~s}^{-1}$ at $\mathrm{pH}$ 5.5 but only $0.02 \mathrm{~s}^{-1}$ at $\mathrm{pH} 8.5$. The large variation in $k_{\mathrm{obs}, \mathrm{T}}$ could be attributed to the varying reactivity of the individual acid-base species of chlorine. At $\mathrm{pH}$ 5.5-8.5, CAP has one major neutral form in solution $\left(\mathrm{pK}_{\mathrm{a}, \mathrm{CAP}}=9.5\right)$ whereas two major acid-base species of chlorine $\left(\mathrm{pK}_{\mathrm{a}, \mathrm{HOCl}}=7.5\right)$ occur under the experimental pH conditions (Duirk et al., 2009; Tian et al., 2014). The speciation of FC is shown in Eqs. (7) and (8) and the $k_{\mathrm{obs}, \mathrm{T}}$ of CAP degradation during chlorination treatment could be expressed as Eq. (9).

$$
[\mathrm{HOCl}]=\frac{\left[\mathrm{H}^{+}\right]}{\left[\mathrm{H}^{+}\right]+\mathrm{K}_{\mathrm{a}, \mathrm{Cl}}}[\mathrm{FC}]
$$

$\left[\mathrm{OCl}^{-}\right]=\frac{\mathrm{K}_{\mathrm{a}, \mathrm{Cl}}}{\left[\mathrm{H}^{+}\right]+\mathrm{K}_{\mathrm{a}, \mathrm{Cl}}}[\mathrm{FC}]$

$$
\frac{d[\mathrm{CAP}]}{d t}=k_{\mathrm{obs}, \mathrm{T}}=k_{\mathrm{app}, 1}[\mathrm{CAP}][\mathrm{HOCl}]+k_{\mathrm{app}, 2}[\mathrm{CAP}]\left[\mathrm{OCl}^{-}\right]
$$

This model allowed the determination of the $k_{\mathrm{app}, 1}$ and $k_{\mathrm{app}, 2}$, via non-linear square regression analysis. Fitting results showed that the second-order rate constant between CAP and $\mathrm{HOCl}\left(k_{\mathrm{app}, 1}\right.$, $\left.23.3 \mathrm{M}^{-1} \mathrm{~s}^{-1}\right)$, is significantly higher than that between CAP and $\mathrm{OCl}^{-}\left(k_{\mathrm{app}, 2}, 1.3 \mathrm{M}^{-1} \mathrm{~s}^{-1}\right)$. The experimental results also well match that from theoretical calculation (Fig. 3A), substantiating the proposed chlorination mechanism.

\subsubsection{Contribution of radicals during the UV/chlorine treatment}

As shown in Fig. 3 , the $k_{\text {obs,T }}$ values of CAP degradation in the $\mathrm{UV} /$ chlorine system were always higher than those in the chlorination system under the tested $\mathrm{pH}$ ranges. Take $\mathrm{pH} 7.0$ for example, the $k_{\mathrm{obs}, \mathrm{T}}$ value in the UV/chlorine system could reach $0.016 \mathrm{~s}^{-1}$, while the $k_{\mathrm{obs}, \mathrm{T}}$ value in the chlorination system was $0.0081 \mathrm{~s}^{-1}$. Although the $k_{\mathrm{obs}, \mathrm{T}}$ values of both the UV/chlorine and chlorination systems similarly exhibited decreasing trends with the increase of $\mathrm{pH}$, the $k_{\mathrm{obs}, \mathrm{T}}$ difference between these systems was larger under alkaline conditions than acidic conditions. At pH 8.5, the $k_{\text {obs, }}$ value in the UV/chlorine system $\left(0.0011 \mathrm{~s}^{-1}\right)$ was 10 folds that in the chlorination system, while at $\mathrm{pH} 7.0$, only a 1.0 fold increase was observed for the $k_{\mathrm{obs}, \mathrm{T}}$ value of UV/chlorine system compared to chlorination system. FC could absorb photons from UV irradiation and produce both $\mathrm{HO} \cdot$ and $\mathrm{Cl} \cdot$ radicals. As a non-selective radical, HO can rapidly degrade a broad range of pollutants, while $\mathrm{Cl} \cdot$ is more selective and it reacts faster with acetic acid and phenol than HO• (Watts and Linden, 2007; Fang et al., 2014). The second rate constant between $\mathrm{HO} \cdot$ and CAP was determined with $2 \times 10^{9} \mathrm{M}^{-1} \mathrm{~s}^{-1}$ (Kapoor and Varshney, 1997). Thus the enhanced CAP degradation could be attributed to the formation of diverse radicals during chlorine photolysis.

The relative contributions of UV irradiation, $\mathrm{HO} \cdot$ and RCSs to the degradation of CAP in the UV/chlorine system were modeled with Eq. (10). The chlorine decay kinetics could be obtained by the DPD method (Fig. S3). The rate constant between $\mathrm{NB}$ and $\mathrm{HO}$ - was determined to be $3.9 \times 10^{9} \mathrm{M}^{-1} \mathrm{~s}^{-1}$, while NB has a very low reactivity with RCSs in the UV/chlorine system (Buxton et al., 1988; Watts and Linden, 2007). Meanwhile, the impact of the trace amounts of NB on the CAP degradation in the system is negligible, as the pseudo-first-order rate constant of CAP in the presence of $10 \mu \mathrm{M}$ of NB were only $5.1 \%$ less than that in the absence of NB. Thus, NB was used in this study as the $\mathrm{HO}^{\bullet}$ probe to calculate the concentration and the contribution of $\mathrm{HO}$ - during the CAP degradation by the UV/chlorine system (Eqs. (11) and (12)) (Xiang et al., 2016).

$$
\begin{aligned}
& \ln \frac{[\mathrm{CAP}]}{[\mathrm{CAP}]_{\mathrm{o}}}=-k_{\mathrm{obs}, \mathrm{T}} t=-\left(k_{\mathrm{UV}}+k_{\mathrm{HO}}+k_{\mathrm{RCSs}}\right) t \\
& k_{\mathrm{HO}}=k_{\mathrm{app}, \mathrm{HO}-\mathrm{CAP} \times\left[\mathrm{HO}^{\circ}\right]_{\mathrm{ss}}} \\
& {\left[\mathrm{HO}^{\circ}\right]_{\mathrm{sS}}=\frac{k_{\mathrm{NB}}}{k_{\mathrm{app}, \mathrm{HO}-\mathrm{NB}}}}
\end{aligned}
$$

where $k_{\mathrm{obs}, \mathrm{T}}$ was the observed pseudo-first-order degradation rate constant $\left(\mathrm{s}^{-1}\right), k_{\mathrm{UV}}$ was the measured pseudo-first-order direct photolysis rate constant $\left(\mathrm{s}^{-1}\right), k_{\mathrm{HO}}{ }^{\bullet}$ and $k_{\mathrm{RCSs}}$ were the pseudo-first-order degradation rate constants $\left(\mathrm{s}^{-1}\right)$ with $\mathrm{HO} \cdot$ and RCSs, respectively, and $k_{\mathrm{app}, \mathrm{HO}}{ }^{\circ}$-CAP and $k_{\mathrm{app}, \mathrm{HO}}{ }^{-\mathrm{NB}}$ were the second order degradation rate constants $\left(\mathrm{M}^{-1} \mathrm{~s}^{-1}\right)$ between $\mathrm{HO} \cdot$ and CAP and NB, respectively.

Based on the calculated results from Eqs. (10)-(12), the contributions of UV irradiation, HO and RCSs to the degradation of CAP in the UV/chlorine were plotted in Fig. 3B. As the $\mathrm{pK}_{\mathrm{a}, \mathrm{CAP}}$ is 9.5, the $k_{\text {UV }}$ value was almost not influenced at pH 5.5-8.5. However, the contribution of $\mathrm{HO} \cdot$ decreased with the increase of $\mathrm{pH}$, which induced the decrease of $k_{\mathrm{obs}, \mathrm{T}}$ subsequently. Previous study reported that the rate constants of $\mathrm{HO}$ radical scavenged by $\mathrm{OCl}^{-}$and $\mathrm{HOCl}$ are $9 \times 10^{9}$ and $2 \times 10^{9} \mathrm{M}^{-1} \mathrm{~s}^{-1}$, respectively (Watts and Linden, 2007). $\mathrm{HO}$ - radical is preferably scavenged by $\mathrm{OCl}^{-}$than by $\mathrm{HOCl}$ under alkaline circumstances. In addition, $\mathrm{HOCl}$ can yield much more $\mathrm{HO}$ radical compared with $\mathrm{OCl}^{-}$. However, the contribution of RCSs in the degradation of CAP by the UV/chlorine 
treatment was less fluctuated compared with $\mathrm{HO} \cdot$. The $k_{\mathrm{RSCs}}$ at $\mathrm{pH}$ 5.5 was $0.0043 \mathrm{~s}^{-1}\left(23.4 \%\right.$ of $\left.k_{\mathrm{obs}, \mathrm{T}}\right)$ and just decreased to $0.0038 \mathrm{~s}^{-1}$ (37.3\% of $k_{\mathrm{obs}, \mathrm{T}}$ ), which could compensate the decreased contribution of $\mathrm{HO} \cdot$ under alkaline circumstances.

The enhanced degradation of CAP by the UV/chlorine process could be attributed to the efficient generation of the chlorine radical species as a result of high UV quantum yields at $254 \mathrm{~nm}$. The quantum yield of $\mathrm{HO} \cdot$ in the UV/chlorine was $1.4 \pm 0.18 \mathrm{Mol} \mathrm{Es}^{-1}$, higher than that of $\mathrm{UV} / \mathrm{H}_{2} \mathrm{O}_{2}$ system $\left(1.0 \mathrm{Mol} \mathrm{Es}^{-1}\right)$ during the UV irradiation (Baxendale and Wilson, 1957; Watts and Linden, 2007). In addition, the scavenger rate in the $\mathrm{UV} /$ chlorine system is significantly lower than that in the $\mathrm{UV} / \mathrm{H}_{2} \mathrm{O}_{2}$ system $\left(8.46 \times 10^{4} \mathrm{M}^{-1} \mathrm{~s}^{-1}(\mathrm{HO} \cdot) \ll 2.7 \times 10^{7} \mathrm{M}^{-1} \mathrm{~s}^{-1}\left(\mathrm{H}_{2} \mathrm{O}_{2}\right)\right.$ (Watts and Linden, 2007)). Provided that the generated radicals were not scavenged by the oxidants themselves, they can effectively contribute to CAP degradation. In addition, due to the low radical scavenging rate by chlorine, a higher chlorine concentration is desirable for decontamination, overcoming the competition of the contaminants and the water matrix for selective oxidants and radical species. However, as DBPs formation commonly accompanies with these advanced oxidation processes and possesses threat to water quality, DBPs formation (species and amount) during and after the UV/chlorine treatment should be evaluated in detail.

\subsection{Formation of HNMs during the UV/chlorine treatment of CAP}

\subsubsection{Effect of the UV/chlorine treatment}

To illustrate the effects of UV/chlorine on the formation of DBPs, synthetic waters with slightly elevated precursor concentrations (i.e., $[C A P]_{o}=50 \mu \mathrm{M}$, UV intensity $=2.1 \mathrm{~mW} \mathrm{~cm}^{-2}$ and a range of UV fluence of $0-3780 \mathrm{~mJ} \mathrm{~cm}^{-2}$ ) were used to evaluate the DBPs formation. Fig. 4 shows the formation of HNMs during and after the $\mathrm{UV} /$ chlorine treatment of CAP at $\mathrm{pH}$ 7.0. Three HNMs (MCNM, DCNM and TCNM) were determined following the degradation of CAP (Fig. 4A, quenched after the sampling).

As a control group, the HNMs formation during the chlorination of CAP was also conducted. The formation of HNMs within $30 \mathrm{~min}$ of chlorination dosing was below LOQs (data not shown in Fig. 4A). Chu et al. (2016) also observed limited HNMs formation during chlorination of CAP, probably due to the fact that FC could not convert nitro and secondary amine group into HNMs. In contrast, when the CAP was exposed to UV/chlorine, HNMs formed immediately ( $4.8 \mu \mathrm{g} \mathrm{L}^{-1} \mathrm{TCNM}$ formation after $1 \mathrm{~min}$ ). After UV/chlorine treatment of 5 min, more than 99\% CAP was removed and the sum of formed MCNM, DCNM and TCNM was $16.5 \mu \mathrm{g} \mathrm{L}^{-1}$. The TCNM formation amount rapidly reached its maximum $\left(32.1 \mu \mathrm{g} \mathrm{L}^{-1}\right)$ at $10 \mathrm{~min}$, and then gradually decreased to $3.3 \mu \mathrm{g} \mathrm{L}^{-1}$ at $30 \mathrm{~min}$. TCNM was the dominant HNMs species before $10 \mathrm{~min}$, while DCNM became the dominant species after $10 \mathrm{~min}$. The dynamic TCNM concentration evolution is possibly caused collectively by the enhanced formation by the UV/chlorine treatment and photolysis by the UV irradiation since TCNM is susceptible to photolysis (Deng et al., 2014). To further substantiate this, the stability of TCNM following UV irradiation $\left(2.1 \mathrm{~mW} \mathrm{~cm}^{-2}\right)$ was monitored. The results showed that after 30 min UV irradiation, > 70\% TCNM was degraded and the concentrations of MCNM and DCNM increased simultaneously (Fig. S4), which was in accordance with the trends in Fig. 4A.

Considering that the DBPs formation may last several days, the DBPsFP experiments (Fig. 4B, analyzed after $24 \mathrm{~h}$ ) were conducted to elucidate the HNMsFP variation after the UV/chlorine treatment. As shown in Fig. 4B, the HNMs formation after $24 \mathrm{~h}$ with different $\mathrm{UV} /$ chlorine treatment time is significantly higher than those formed during the UV/chlorine treatment. For example, the

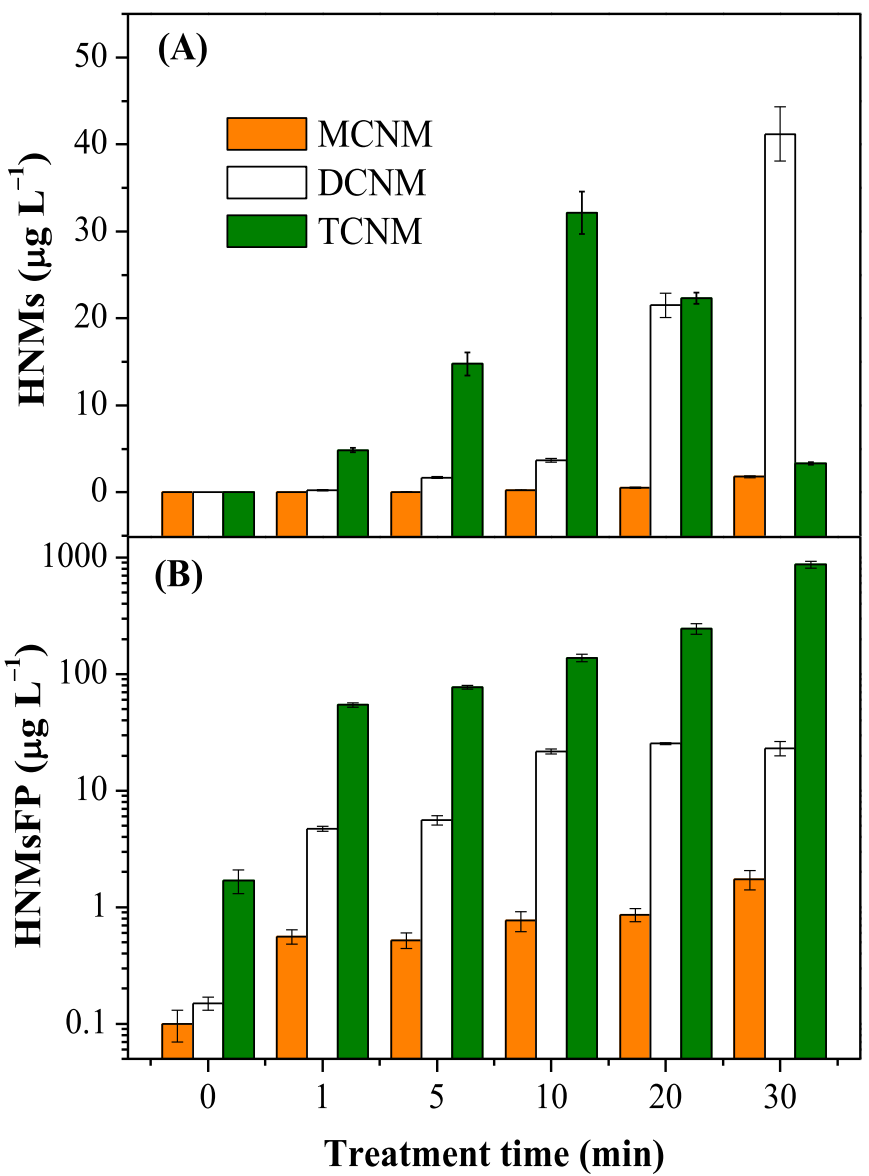

Fig. 4. Effect of treatment time on the simultaneous HNMs formation (A) and HNMsFP $(24 \mathrm{~h})$ (B) from CAP by UV/chlorine treatment. Experimental conditions: $[\mathrm{CAP}]_{\mathrm{o}}=50 \mu \mathrm{M}$, [chlorine $]_{\mathrm{o}}=0.5 \mathrm{mM}$, [treatment time $]_{\mathrm{o}}=0-30 \mathrm{~min}$, UV intensity $=2.1 \mathrm{~mW} \mathrm{~cm}{ }^{-2}$, pH 7.0 adjusted by $2 \mathrm{mM}$ phosphate buffer, $\mathrm{T}=25^{\circ} \mathrm{C}$. Error bars represent the $95 \%$ confidence interval.

simultaneous formed amounts of MCNM, DCNM and TCNM by the $\mathrm{UV} /$ chlorine treatment of $5 \mathrm{~min}$ were $0.1,1.6$ and $14.8 \mu \mathrm{g} \mathrm{L}^{-1}$, respectively (Fig. 4A), while their 24 -h formed amounts can reach $0.1,5.6$ and $77.4 \mu \mathrm{g} \mathrm{L}^{-1}$, respectively. It was clear that the UV/ chlorine treatment enhanced the HNMs formation and the enhancement was highly dependent on the UV/chlorine treatment time. Although the TCNM formation decreased with prolong irradiation times (Fig. 4A), the HNMsFP result (after $24 \mathrm{~h}$ ) still positively correlated with the treatment time. Compared to the chlorination alone, $5 \mathrm{~min} \mathrm{UV/chlorine} \mathrm{treatment} \mathrm{enhanced} \mathrm{the} \mathrm{24-}$ $\mathrm{h}$ formation of MCNM, DCNM and TCNM by about 5.2, 37.3, and 45.5 folds, respectively, indicating the structure of CAP was changed to being prone to the formation of HNMs by the UV/chlorine treatment.

\subsubsection{Effect of initial chlorine concentration}

The effect of chlorine dosage $(0.05-2.0 \mathrm{mM})$ on the HNMs formation after a 10-min UV/chlorine treatment was measured (Fig. 5). Chlorine dosage impacted not only the concentration of HNMs, but also the dominant species of HNMs. The TCNM formation increased significantly with increasing chlorine dosage, while MCNM and DCNM formation exhibited decreasing trends (especially for DCNM). In the range of $0.05-0.1 \mathrm{mM}$ of chlorine, DCNM was the dominant HNMs species. When the initial chlorine concentration was $\geq 0.1 \mathrm{mM}$, TCNM became the dominant HNMs species. The decrease in MCNM and DCNM and increase in TCNM 


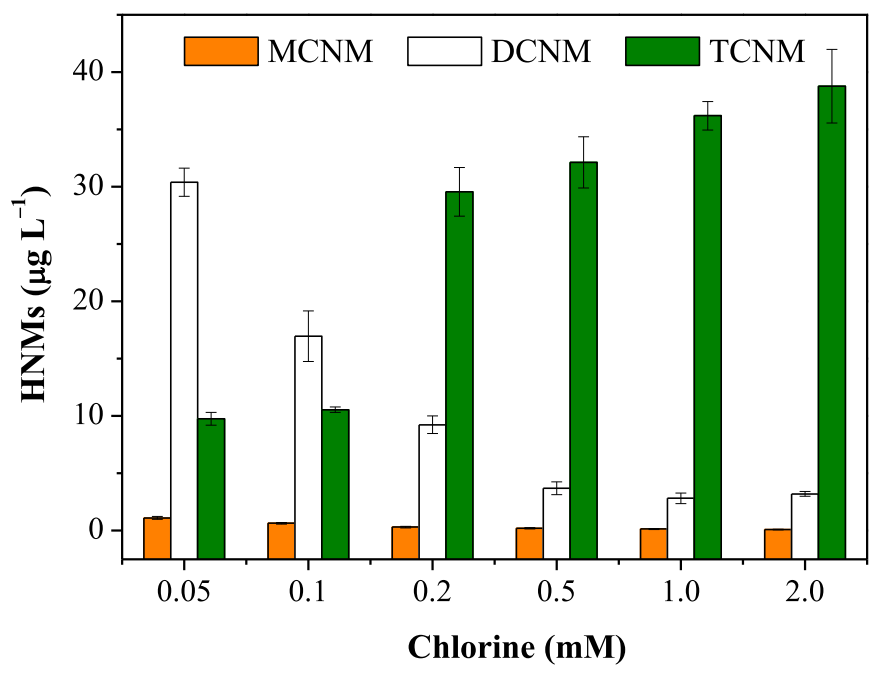

Fig. 5. Effect of initial chlorine concentration on the simultaneous formation of HNMs after a 10 -min treatment of CAP by UV/chlorine treatment. Experimental conditions: $[\mathrm{CAP}]_{\mathrm{o}}=50 \mu \mathrm{M}$, treatment time $=10 \mathrm{~min}$, UV intensity $=2.1 \mathrm{~mW} \mathrm{~cm}{ }^{-2}, \mathrm{pH} 7.0$ adjusted by $2 \mathrm{mM}$ phosphate buffer, $\mathrm{T}=25^{\circ} \mathrm{C}$. Error bars represent the $95 \%$ confidence interval.

concentration at relatively high chlorine concentrations demonstrated the transformation of MCNM and DCNM to TCNM. Although the TCNM concentration may decrease with the prolongation of irradiation time, the photolysis of TCNM was limited when the UV fluence was $<1260 \mathrm{~mJ} \mathrm{~cm}^{-2}$ (10 min) (Fig. 4A). Deng et al. (2014) also observed that the TCNM formation potential under combined $\mathrm{UV} /$ chlorine conditions is linearly dependent on the FC concentration, consistent with our results.

\subsubsection{Effect of $p H$}

The effect of $\mathrm{pH}$ on the formation of HNMs during the UV/ chlorine treatment of CAP was investigated at $\mathrm{pH}$ 5.5-8.5 (Fig. 6). Under the UV/chlorine treatment, the MCNM, DCNM and TCNM formations were generally higher at low $\mathrm{pHs}$ than at high $\mathrm{pHs}$. For example, the simultaneous formation of TCNM (at $10 \mathrm{~min}$ ) was 82.2, 32.1, and $2.8 \mu \mathrm{g} \mathrm{L}^{-1}$ at $\mathrm{pH} 5.5,7.0$, and 8.5, respectively (Fig. 5C). The formation of MCNM and DCNM during the UV/chlorine treatment of CAP exhibited similar pH dependency. Interestingly, previous studies reported a contradictory $\mathrm{pH}$ dependency for the formation of HNMs during chlorination, with more TCNM forming at alkaline circumstances than at neutral and acidic conditions (Joo and Mitch, 2007; Shan et al., 2012). Because HNMs are formed from the oxidative degradation of CAP (following the formation of radicals) and their formation was rather limited during chlorination alone, chemically it makes sense that HNMs formation was enhanced at acidic conditions (since the oxidation of CAP via HO• was more effective under acidic condition, Fig. 3B). As the HNMs formation during the chlorination of CAP is rather limited, the accelerated oxidation of CAP under acidic and neutral circumstances by the UV/chlorine treatment is the prerequisite for the formation of HNMs. As mentioned in Fig. 3B, the oxidation of CAP via $\mathrm{HO}$ - was more effective under acidic and neutral circumstances, which facilitated the HNMs formation subsequently.

\subsubsection{Effect of bromide}

Bromide ion $\left(\mathrm{Br}^{-}\right)$is ubiquitous in many water sources. $\mathrm{Br}^{-}$ concentrations in the water sources of United States and China were reported around 100 and 200-600 $\mu \mathrm{g} \mathrm{L}^{-1}$, respectively (Westerhoff et al., 1994; Lu et al., 2011). The presence of $\mathrm{Br}^{-}$in source waters can shift the DBPs to brominated-HNMs (Br-HNMs),

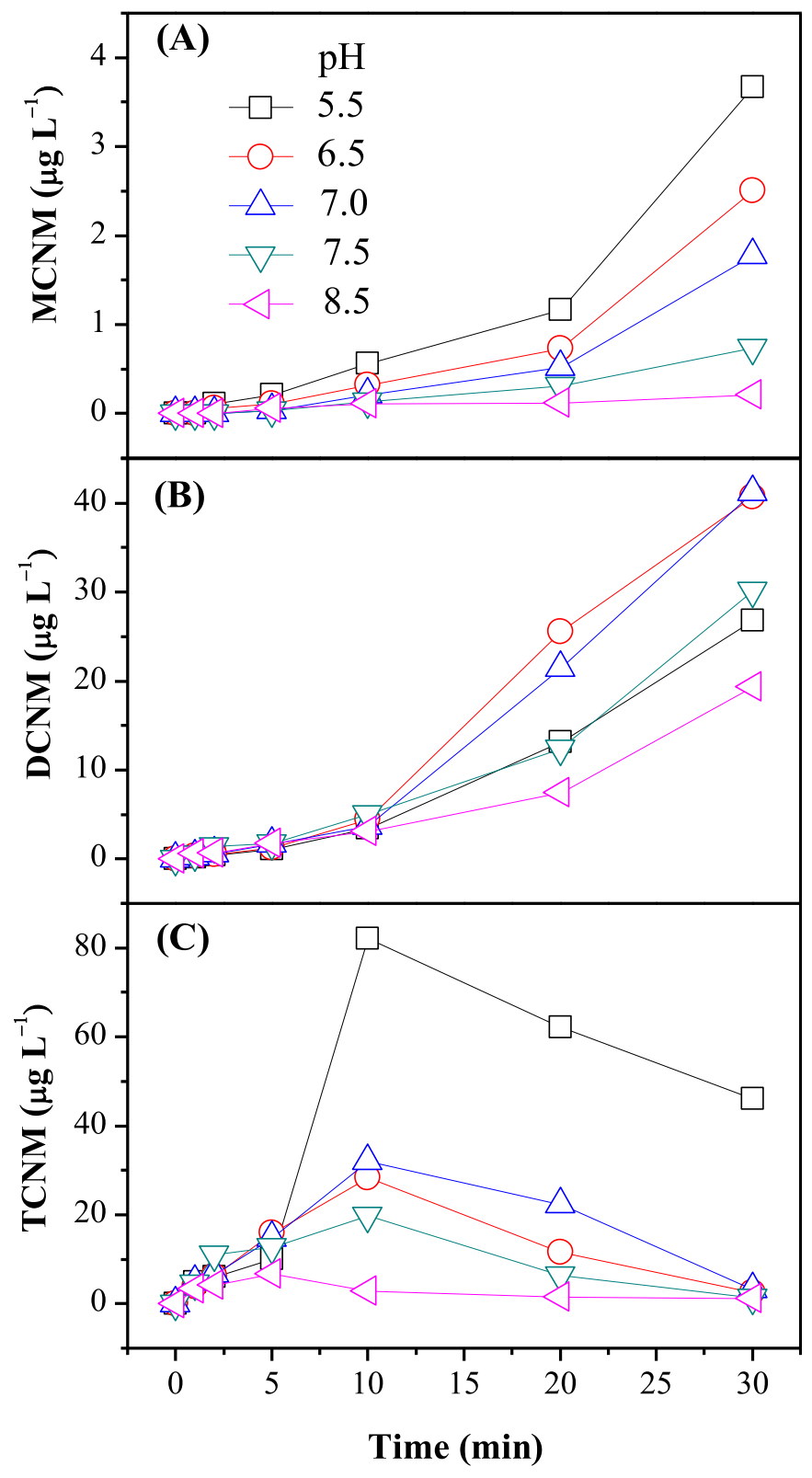

Fig. 6. Effect of pH on the formation profiles of MCNM (A), DCNM (B) and TCNM (C) during the UV/chlorine treatment of CAP. Experimental conditions: $[C A P]_{o}=50 \mu \mathrm{M}$, [chlorine $]_{\mathrm{o}}=0.5 \mathrm{mM}$, treatment time $=0-30 \mathrm{~min}$, UV intensity $=2.1 \mathrm{~mW} \mathrm{~cm}{ }^{-2}, \mathrm{pH}$ 7.0 adjusted by $2 \mathrm{mM}$ phosphate buffer, $\mathrm{T}=25^{\circ} \mathrm{C}$.

which are more toxic than chlorinated-HNMs (Cl-HNMs). Fig. 7 shows the speciation and concentration of $\mathrm{Cl}-\mathrm{HNMs}$ and $\mathrm{Br}$ HNMs during the UV/chlorine treatment of CAP with different initial $\mathrm{Br}^{-}$concentrations. The increase of initial $\mathrm{Br}^{-}$concentration from 0 to $1.0 \mathrm{mg} \mathrm{L}^{-1}$ did not increase the total amount of HNMs formation, but shifted the relative abundance of $\mathrm{Cl}-\mathrm{HNM}$ and $\mathrm{Br}$ HNMs. Although the TCNM concentration decreased with increasing initial $\mathrm{Br}^{-}$concentrations, TCNM was always the dominant species, even when the concentration of $\mathrm{Br}^{-}$was $1.0 \mathrm{mg} \mathrm{L}^{-1}$. However, increasing $\mathrm{Br}^{-}$concentration notably shifted the HNMs towards those containing more bromine (e.g., DBMCNM and TBNM). Overall, the formation of Br-HNMs is enhanced at increasing initial $\mathrm{Br}^{-}$concentration during the $\mathrm{UV} /$ chlorine treatment. Similar to chlorination treatment, $\mathrm{Br}^{-}$can be easily oxidized by FC into hypobromous acid during the UV/chlorine treatment. 


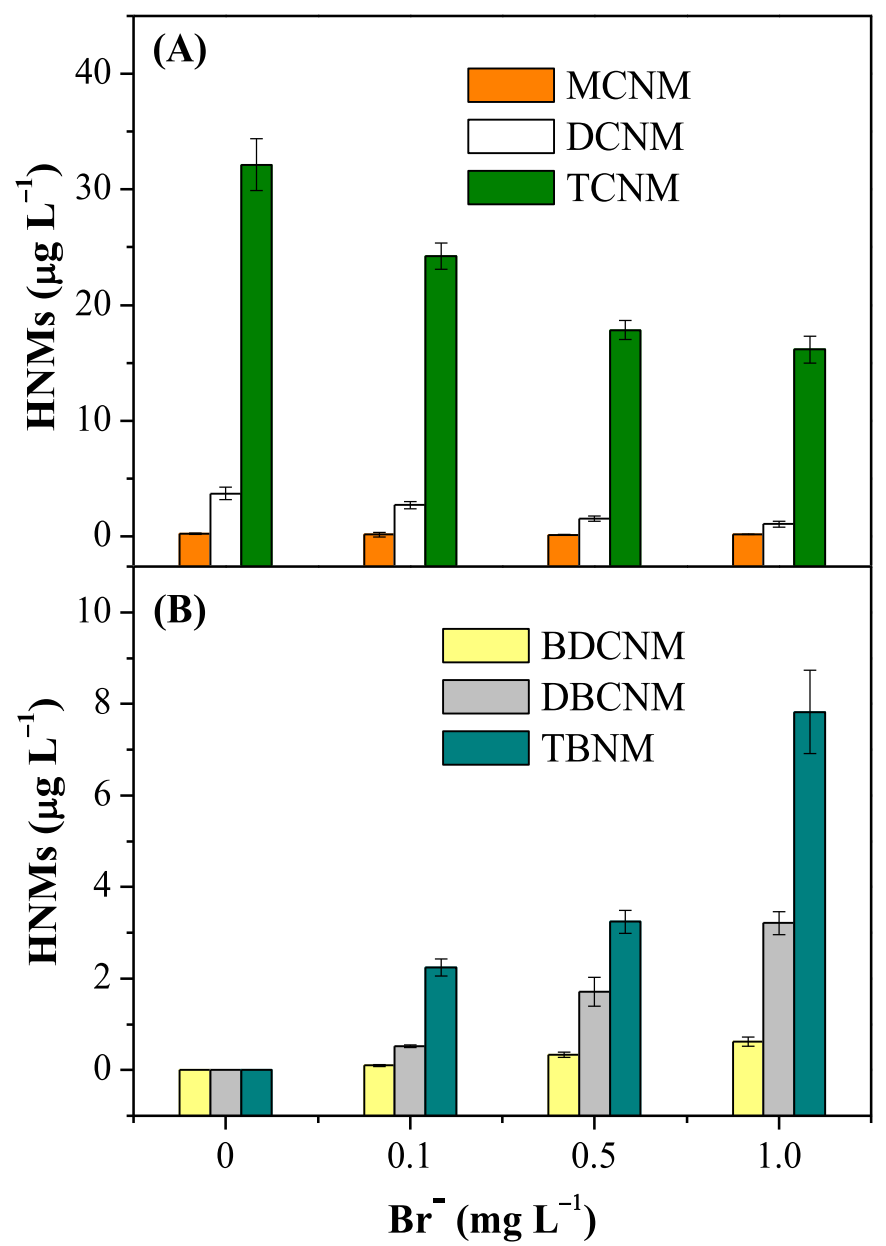

Fig. 7. Effect of initial $\mathrm{Br}^{-}$concentration on the Cl-HNMs (A) and Br-HNMs (B) formation amounts during the UV/chlorine treatment of CAP. Experimental conditions: $[\mathrm{CAP}]_{\mathrm{o}}=50 \mu \mathrm{M}$, [chlorine $]_{\mathrm{o}}=0.5 \mathrm{mM}$, treatment time $=10 \mathrm{~min}$, UV intensity $=2.1 \mathrm{~mW} \mathrm{~cm}^{-2}$, $\mathrm{pH} 7.0$ adjusted by $2 \mathrm{mM}$ phosphate buffer, $\mathrm{T}=25^{\circ} \mathrm{C}$. Error bars represent the $95 \%$ confidence interval.

Hypobromous acid could take substitution reaction with organics at a much faster rate than $\mathrm{HOCl}$, which subsequently promoted the formation of Br-HNMs.

\subsection{Proposed degradation steps of CAP during the UV/chlorine treatment}

After the oxidation of CAP in the UV/chlorine system, the TBPs were analyzed by UPLC-MS/MS to reveal the CAP degradation and HNMs formation steps. Table S1 summarizes the main fragment ions of CAP TBPs and the proposed molecular formulas. The TIC and SIM chromatograms obtained by UPLC-MS/MS analysis are provided in Figs. S5 and S6, respectively. The dehydration product of CAP (TBP $1, \mathrm{~m} / \mathrm{z} 304$ ) was firstly observed during the reaction, indicating the quick transformation of parent structure of CAP during oxidation. Two main possible degradation steps of CAP are proposed in Fig. 8. As mentioned above, the combination of UV and chlorine can generate reactive radical species such as $\mathrm{Cl}^{\bullet}, \mathrm{Cl}_{2}^{-}$and HO•, which would facilitate the degradation of CAP. After the dehydration, the $-\mathrm{C}-\mathrm{N}-$ bonds were broke by the diverse radials in the UV/chlorine system, which induced the formation of TBP 2 and TBP 7.

Chlorine could oxidize the nitrogen in amine precursors from their -3 oxidation state to $\mathrm{a}+3$ nitro group (Shah and Mitch, 2012).

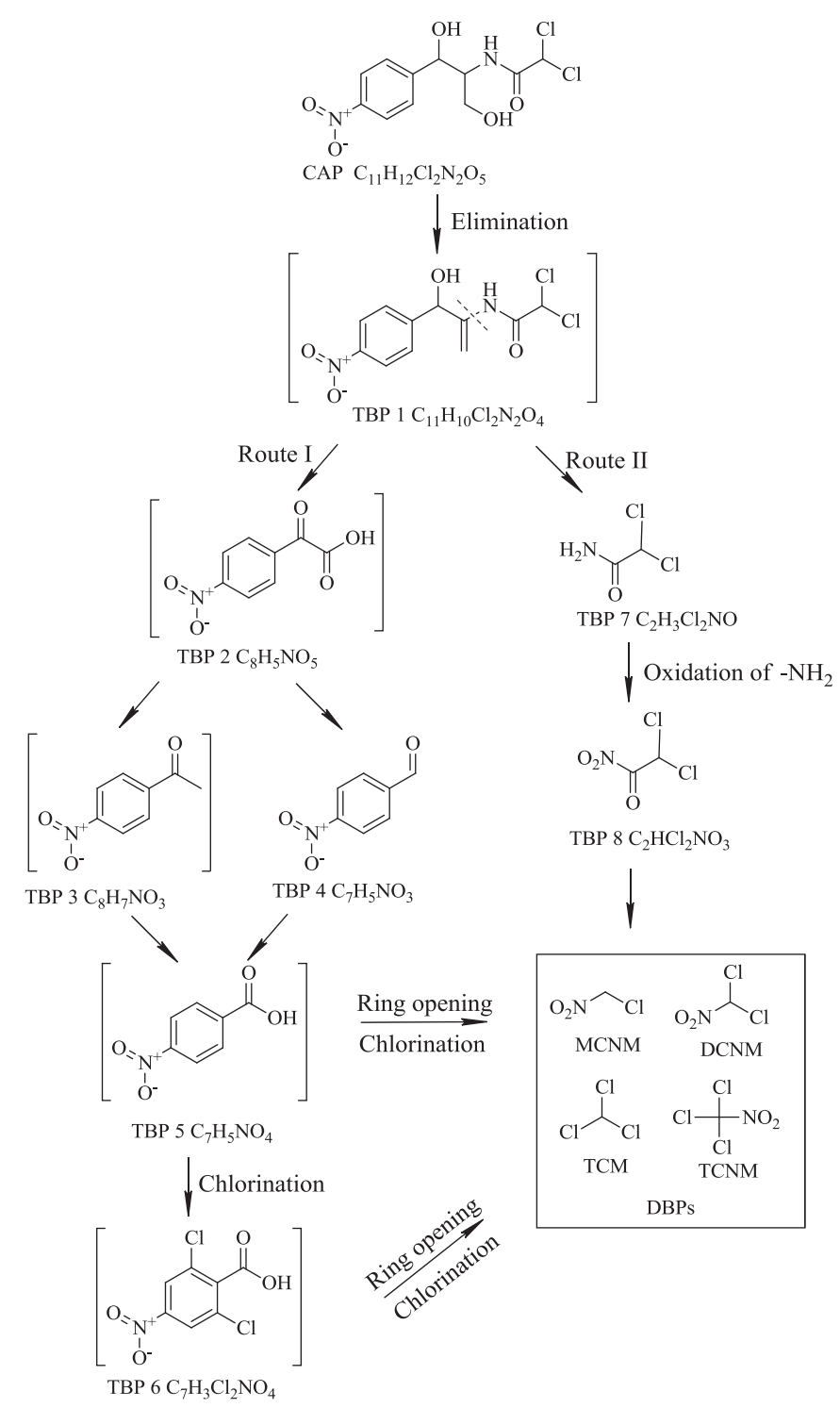

Fig. 8. Proposed CAP degradation and DBPs formation steps by the UV/chlorine treatment.

Although the structure of CAP contains a secondary amine group, Fig. $4 \mathrm{~B}$ clearly shows that the formation of TCNM during the chlorination of CAP is rather limited, indicating chlorine cannot transform the secondary amine and nitro groups of CAP into TCNM. After the cleavage $-\mathrm{C}-\mathrm{N}-$ bonds by the $\mathrm{UV} /$ chlorine, it is chemically sound to propose that radical species such as $\mathrm{Cl} \cdot \mathrm{Cl}^{\circ}-\overline{2}$ and $\mathrm{HO} \cdot$ radicals can be more effective in oxidizing the secondary amine to nitroalkane intermediate (TBP 8), and thus promote the formation HNMs. Meanwhile, with the attack of diverse radicals, both the liberation of nitrite and the ring open at the aromatic carbon atom closest to the nitro group may facilitate the formation of HNMs simultaneously (TBPs 3, 4, 5 and 6). In addition, the TCM formation in the UV/chlorine system was significantly higher than in the chlorination system (Fig. S7), indicating the strong oxidation abilities of HO• and RCSs and the enhanced formation of low molecular weight TBPs during the UV/chlorine treatment.

\section{Conclusions}

Based on the experimental results, the following conclusions 
can be drawn:

- The $k_{\mathrm{obs}, \mathrm{T}}$ of the UV/chlorine process at $\mathrm{pH} 7.0$ was $0.016 \mathrm{~s}^{-1}$, which was 10.0 and 2.0 folds that observed in the UV and chlorination systems, respectively.

- The acceleration can be attributed to the formations of $\mathrm{HO}$ and RCSs, and the contribution of RCSs was stable at pH 5.5-8.5.

- Both the formation of HNMs and 24-h HNMsFP during the UV/ chlorine treatment were enhanced, which were positively proportional to the UV/chlorine treatment time.

- The formations of diverse radicals during the UV/chlorine treatment not only promote the CAP degradation, but also enhance the DBPs formation.

\section{Acknowledgments}

This work was financially supported by the National Natural Science Foundation of China (51408590, 51290281, 51525806), Chinese Academy of Sciences (QYZDY-SSW-DQC004), Ministry of Housing and Urban-Rural Development of China (2017ZX07207004) and CAS/SAFEA International Partnership Program for Creative Research Teams of China.

\section{Appendix A. Supplementary data}

Supplementary data related to this article can be found at http:// dx.doi.org/10.1016/j.watres.2017.05.030.

\section{References}

APHA, AWWA, WEF, 1998. Standard Methods for the Examination of Water and Wastewater, twenty-second ed. APHA Publication Office, Washington, DC.

Baxendale, J.H., Wilson, J.A., 1957. The photolysis of hydrogen peroxide at high light intensities. Trans. Faraday Soc. 53 (3), 344-356.

Beitz, T., Bechmann, W., Mitzner, R., 1998. Investigations of reactions of selected azaarenes with radicals in water. 2. Chlorine and bromine radicals. J. Phys. Chem. A 102 (34), 6766-6771.

Bolton, J.R., Linden, K.G., 2003. Standardization of methods for fluence (UV dose) determination in bench-scale UV experiments. J. Environ. Eng. 129 (3), 209-215.

Buxton, G.V., Greenstock, C.L., Helman, W.P., Ross, A.B., 1988. Critical review of rate constants for reactions of hydrated electrons, hydrogen atoms and hydroxyl radicals $\left(\cdot \mathrm{OH} / \cdot \mathrm{O}^{-}\right)$in aqueous solution. J. Phys. Chem. Ref. Data 17 (2), $513-886$.

Chan, P.Y., Gamal El-Din, M., Bolton, J.R., 2012. A solar-driven UV/Cl 2 advanced oxidation process. Water Res. 46 (17), 5672-5682.

Chu, W.H., Gao, N.Y., Templeton, M.R., Yin, D.Q., 2011. Comparison of inclined plate sedimentation and dissolved air flotation for the minimisation of subsequent nitrogenous disinfection by-product formation. Chemosphere 83 (5), 647-651.

Chu, W.H., Li, D.M., Gao, N.Y., Templeton, M.R., Tan, C.Q., Gao, Y.Q., 2014. The control of emerging haloacetamide DBP precursors with UV/persulfate treatment. Water Res. 72 (SI), 340-348.

Chu, W.H., Chu, T.F., Bond, T., Du, E.D., Guo, Y.Q., Gao, N.Y., 2016. Impact of persulfate and ultraviolet light activated persulfate pre-oxidation on the formation of trihalomethanes, haloacetonitriles and halonitromethanes from the chlor(am) ination of three antibiotic chloramphenicols. Water Res. 93, 48-55.

Deng, L., Huang, C.H., Wang, Y.L., 2014. Effects of combined UV and chlorine treatment on the formation of trichloronitromethane from amine precursors. Environ. Sci. Technol. 48 (5), 2697-2705.

Dong, H.Y., Yuan, X.J., Wang, W.D., Qiang, Z.M., 2016. Occurrence and removal of antibiotics in ecological and conventional wastewater treatment processes: a field study. J. Environ. Manage. 178 (1), 11-19.

Duirk, S.E., Desetto, L.M., Davis, G.M., 2009. Transformation of organophosphorus pesticides in the presence of aqueous chlorine: kinetics, pathways, and structure-activity relationships. Environ. Sci. Technol. 43 (7), 2335-2340.

Fang, J.Y., Fu, Y., Shang, C., 2014. The roles of reactive species in micropollutant degradation in the UV/free chlorine system. Environ. Sci. Technol. 48 (3), 1859-1868.
Feng, Y.G., Smith, D.W., Bolton, J.R., 2007. Photolysis of aqueous free chlorine species ( $\mathrm{HOCl}$ and $\mathrm{OCl}^{-}$) with $254 \mathrm{~nm}$ ultraviolet light. J. Environ. Eng. Sci. 6 (3), 277-284.

Garoma, T., Gurol, M.D., 2005. Modeling aqueous ozone/UV process using oxalic acid as probe chemical. Environ. Sci. Technol. 39 (20), 7964-7969.

Grebel, J.E., Pignatello, J.J., Mitch, W.A., 2010. Effect of halide ions and carbonates on organic contaminant degradation by hydroxyl radical-based advanced oxidation processes in saline waters. Environ. Sci. Technol. 44 (17), 6822-6828.

Hirakawa, T., Nosaka, Y., 2002. Properties of $\mathrm{O}_{2}$ and $\mathrm{OH}$ formed in $\mathrm{TiO}_{2}$ aqueous suspensions by photocatalytic reaction and the influence of $\mathrm{H}_{2} \mathrm{O}_{2}$ and some ions. Langmuir 18 (8), 3247-3254.

Jiang, L., Hu, X.L., Yin, D.Q., Zhang, H.C., Yu, Z.Y., 2011. Occurrence, distribution and seasonal variation of antibiotics in the Huangpu River, Shanghai, China. Chemosphere 82 (6), 822-828.

Joo, S.H., Mitch, W.A., 2007. Nitrile, aldehyde, and halonitroalkane formation during chlorination/chloramination of primary amines. Environ. Sci. Technol. 41 (4), 1288-1296.

Kapoor, S., Varshney, L., 1997. Redox reactions of chloramphenicol and some aryl peroxy radicals in aqueous solutions: a pulse radiolysis study. J. Phys. Chem. 101 (42), 7778-7782.

Krasner, S.W., Weinberg, H.S., Richardson, S.D., Pastor, S.J., Chinn, R., Sclimenti, M.J., Onstad, G.D., Thruston, A.D., 2006. Occurrence of a new generation of disinfection byproducts. Environ. Sci. Technol. 40 (23), 7175-7185.

Lee, Y., von Gunten, U., 2010. Oxidative transformation of micropollutants during municipal wastewater treatment: comparison of kinetic aspects of selective (chlorine, chlorine dioxide, ferrate ${ }^{\mathrm{VI}}$, and ozone) and non-selective oxidants (hydroxyl radical). Water Res. 44 (2), 555-566.

Liu, W., Cheung, L.M., Yang, X., Shang, C., 2006. THM, HAA and CNCl formation from UV irradiation and chlor(am)ination of selected organic waters. Water Res. 40 (10), 2033-2043.

Lu, N., Huang, X., Gao, N.Y., Liu, H., Zhang, D., 2011. Bromonium ion and its bromate formation potential in raw water of Qingcaosha Reservoir. Water Purif. Technol. 30 (3), 10-12, 19.

Mompelat, S., Le Bot, B., Thomas, O., 2009. Occurrence and fate of pharmaceutical products and by-products, from resource to drinking water. Environ. Int. 35 (5), 803-814.

Munch, D., Hautman, D., 1995. US EPA Method 551.1 Determination of Chlorination Disinfection Byproducts, Chlorinated Solvents, and Halogenated Pesticides/ Herbicides in Drinking Water by Liquid-liquid Extraction and Gas Chromatography with Electron Capture Detection. US EPA, Cincinnati, Ohio.

Sapkota, A., Sapkota, A.R., Kucharski, M., Burke, J., McKenzie, S., Walker, P. Lawrence, R., 2008. Aquaculture practices and potential human health risks: current knowledge and future priorities. Environ. Int. 34 (8), 1215-1226.

Shah, A.D., Mitch, W.A., 2012. Halonitroalkanes, halonitriles, haloamides, and Nnitrosamines: a critical review of nitrogenous disinfection byproduct formation pathways. Environ. Sci. Technol. 46 (1), 119-131.

Shan, J., Hu, J., Kaplan-Bekaroglu, S.S., Song, H., Karanfil, T., 2012. The effects of pH, bromide and nitrite on halonitromethane and trihalomethane formation from amino acids and amino sugars. Chemosphere 86 (4), 323-328.

Shao, B., Chen, D., Zhang, J., Wu, Y.N., Sun, C.J., 2009. Determination of 76 pharmaceutical drugs by liquid chromatography-tandem mass spectrometry in slaughterhouse wastewater. J. Chromatogr. A 1216 (47), 8312-8318.

Sichel, C., Garcia, C., Andre, K., 2011. Feasibility studies: $\mathrm{UV} / \mathrm{Cl}_{2}$ advanced oxidation treatment for the removal of emerging contaminants. Water Res. 45 (19), 6371-6380.

Soltermann, F., Lee, M., Canonica, S., von Gunten, U., 2013. Enhanced N-nitrosamine formation in pool water by UV irradiation of chlorinated secondary amines in the presence of monochloramine. Water Res. 47 (1), 79-90.

Tian, F., Liu, W.J., Guo, G., Qiang, Z.M., Zhang, C., 2014. Kinetics and mechanism of dimethoate chlorination during drinking water treatment. Chemosphere 103, $181-187$.

Watts, M.J., Linden, K.G., 2007. Chlorine photolysis and subsequent OH radical production during UV treatment of chlorinated water. Water Res. 41 (13), 2871-2878.

Weng, S.C., Li, J., Blatchley, E.R., 2012. Effects of UV254 irradiation on residual chlorine and DBPs in chlorination of model organic-N precursors in swimming pools. Water Res. 46 (8), 2674-2682.

Westerhoff, P., Siddiqui, M.S., Debroux, J., Zhai, W., Ozekin, K., Amy, G., 1994. Nationwide bromide occurrence and bromate formation potential in drinking water supplies. In: Ryan, J.N., Edwards, M. (Eds.), Critical Issues in Water and Wastewater Treatment. American Society of Civil Engineers, New York.

Xiang, Y.Y., Fang, J.Y., Shang, C., 2016. Kinetics and pathways of ibuprofen degradation by the UV/chlorine advanced oxidation process. Water Res. 90, 301-308.

Xu, W.H., Zhang, G., Zou, S.C., Li, X.D., Liu, Y.C., 2007. Determination of selected antibiotics in the Victoria Harbour and the Pearl River, South China using highperformance liquid chromatography-electrospray ionization tandem mass spectrometry. Environ. Pollut. 145 (3), 672-679. 